\title{
Concurrent Removal and Reduction of Cr(VI) by Wool: Short and Long Term Equilibration Studies
}

\author{
Fawwaz H. Jumean ${ }^{1}$, Mustafa I. Khamis ${ }^{1,2}$, Ziad A. Sara1, Mahmoud S. AbouRich1 \\ ${ }^{1}$ Department of Biology, Chemistry and Environmental Sciences, American University of Sharjah, Sharjah, \\ United Arab Emirates \\ ${ }^{2}$ Department of Chemistry and Chemical Technology, Faculty of Science \& Technology, Al-Quds University, \\ East Jerusalem, Palestine \\ Email: fjumean@aus.edu
}

Received 19 October 2014; revised 5 December 2014; accepted 23 December 2014

Copyright (C) 2015 by authors and Scientific Research Publishing Inc.

This work is licensed under the Creative Commons Attribution International License (CC BY).

http://creativecommons.org/licenses/by/4.0/

(c) (i) Open Access

\begin{abstract}
Hexavalent chromium removal from wastewater using sheep wool was investigated at several equilibration periods. The influence of contact time, $\mathrm{pH}$, adsorbent dosage and initial concentration was investigated. Adsorption isotherms for long and short periods were fitted to the Langmuir and Freundlich isotherms. For short contact times, the Langmuir adsorption isotherm was obeyed with no detectable change in the oxidation state but removal percentages did not exceed $\mathbf{9 0 \%}$. Long contact times resulted in more than $99 \%$ removal of $\mathrm{Cr}(\mathrm{VI})$. A 2-step mechanism for the removal is proposed. Free wool and wool loaded with $\mathrm{Cr}(\mathrm{VI})$ were characterized by FTIR and SEM.
\end{abstract}

\section{Keywords}

Chromium, Wool, Speciation, Adsorption Isotherms

\section{Introduction}

Chromium can exist in various valence states ranging from $\mathrm{Cr}$ (II) to $\mathrm{Cr}$ (VI), the most stable forms being $\mathrm{Cr}$ (III) and Cr(VI) [1]-[3]. These two forms exhibit large differences in physicochemical properties as well as chemical and biochemical reactivity [2] [3]. Cr(III) is relatively insoluble in water and is an essential micronutrient, whereas $\mathrm{Cr}(\mathrm{VI})$ is water soluble and is a primary contaminant due to its toxicity to humans, animal, plants and microorganisms and could also be carcinogenic [3] [4]. Chromium has widespread industrial applications that span

"Corresponding author.

How to cite this paper: Jumean, F.H., Khamis, M.I., Sara, Z.A. and AbouRich, M.S. (2015) Concurrent Removal and Reduction of $\mathrm{Cr}(\mathrm{VI})$ by Wool: Short and Long Term Equilibration Studies. American Journal of Analytical Chemistry, 6, 47-57. http://dx.doi.org/10.4236/ajac.2015.61005 
the pharmaceutical industry, mining, leather tanning, textile dying, electroplating, aluminum conversion, coating operations, inorganic pigments industry, and wood preservatives [3] [5]. This pervasive use results in the discharge of large quantities of chromium into the environment. Accordingly, environmental scientists are paying increasing attention to reducing chromium levels in wastewater. A variety of methods have been adapted for removal of $\mathrm{Cr}(\mathrm{VI})$ from wastewater. These include reduction followed by chemical precipitation [6], ion exchange [7], reduction [8], adsorption [9], electrochemical precipitation [10], solvent extraction [11], membrane separation [12], cementation [13], evaporation, reverse osmosis, foam separation, freeze separation, and biosorption [14].

Adsorption is an effective and versatile method for removing Cr(VI). Several publications report on the use of low cost and locally abundant adsorbents such as activated carbon [15], agricultural byproducts [16], waste materials [17], and minerals [18].

In our laboratory, we have compared the effectiveness of several low cost adsorbents in removing Cr(VI) from industrial wastewater. These include sheep wool, olive cake, sawdust, pine needles, almond shells, cactus leaves and charcoal, and have reported that wool was the most efficient adsorbent for speciation and removal of $\mathrm{Cr}(\mathrm{VI})$ [3]. However, in that study, batch mode adsorption isotherms revealed that at the optimum conditions, total chromium removal never exceeded $90 \%$ after 3-hour equilibration. In this work, we propose an efficient and low cost method that yields complete removal of $\mathrm{Cr}(\mathrm{VI})$ from wastewater while partially converting it to the essential micronutrient Cr(III). Several reports in the literature conclude that natural adsorbents [15] [16] [20], micelle-clay complexes [21] and polymeric materials [22] can reduce $\mathrm{Cr}$ (VI) to $\mathrm{Cr}$ (III). Speciation between $\mathrm{Cr}(\mathrm{VI})$ and $\mathrm{Cr}(\mathrm{III})$ can be achieved by a combination of spectrophotometric [23] and inductively coupled plasma (ICP) measurements. The effect of $\mathrm{pH}$, contact time, and particle size is studied and explained in terms of the capacity of wool to adsorb and reduce Cr(VI) to $\mathrm{Cr}(\mathrm{III})$.

\section{Experimental}

\subsection{Chemicals}

All primary chemicals used were of analytical reagent grade. Potassium chromate $\left(\mathrm{K}_{2} \mathrm{CrO}_{4}\right)$ and chromium (III) chloride hexahydrate $\left(\mathrm{CrCl}_{3} \cdot 6 \mathrm{H}_{2} \mathrm{O}\right)$ were purchased from Riedel De-Haen. Sodium hydroxide, hydrochloric, sulfuric, and nitric acids were purchased from Paneac. 1,5 di-phenyl carbazide, and acetone were obtained from Sigma Aldrich. The wool was washed with water and detergent for two days. The adsorbent used in the study was sheep wool, freshly trimmed from sheep in the Sharjah animal market. It was carefully cleaned, riffled, separated from impurities then air-dried. It was finally sized into 2-cm long fibers and placed in a sealed container labelled "original wool". A portion of this wool was freeze-dried in liquid nitrogen for 10 min and then milled. Powder below 0.60 mm (mesh 30) was labelled “powdered wool”.

\subsection{Instrumentation}

Total chromium was determined using Varian Liberty axial sequential inductively coupled plasma-atomic emission spectrometer (ICP-AES, Varian, Australia). Cr (VI) concentrations were determined spectrophotometrically using Cary a 50 spectrophotometer (Varian, Australia). IR spectra were recorded using Spectrum One FTIR spectrometer (Perkin Elmer, USA). pH was measured by Thermo-Orion 210A+ pH meter (USA) using a combined glass electrode calibrated with buffers of $\mathrm{pH} 4.0,7.0$, and 10.0. Solutions were shaken using Edmund Buhler KS-15/TH-15 shaker (Germany) and their temperature was maintained at $25.0^{\circ} \pm 0.1^{\circ}$. Scanning electron microscopy (SEM) was performed on a Tescan VEGA III LMU (Czech Republic). Electron dispersive x-ray spectroscopy (EDS) was recorded on Oxford Instruments INCA XMAX (UK).

\subsection{Methods}

Stock solutions containing 500 ppm Cr(VI) were prepared by dissolving potassium dichromate in deionized water. Standard solutions of 10, 20, 50, 100, 150 \& 200 ppm were prepared by dilution. Stock ligand solutions were prepared by dissolving 1,5 diphenyl carbazide in acetone.

Batch adsorption studies were carried out in flasks containing $100 \mathrm{ml}$ of test solutions at the desired initial chromium concentrations. $\mathrm{pH}$ was adjusted using either $0.10 \mathrm{M} \mathrm{HCl}$ or $0.10 \mathrm{M} \mathrm{NaOH}$. Wool was then placed in the flasks and the contents shaken for 3 -h at $25.0^{\circ} \mathrm{C}$ and $150 \mathrm{rpm}$. At known equilibration times, aliquots were 
withdrawn and analyzed for total chromium and $\mathrm{Cr}(\mathrm{VI})$.

Spectrophotometry was used to determine $\operatorname{Cr}(\mathrm{VI})$ concentrations using 1,5 di-phenyl carbazide. A $0.10 \mathrm{ml}$ aliquot was collected and mixed with $0.20 \mathrm{ml}$ of this ligand and 2 drops of $6.0 \mathrm{M}$ sulfuric acid and the volume adjusted to $10 \mathrm{ml}$. The $\mathrm{Cr}(\mathrm{VI})$-ligand complex was allowed to equilibrate for $10 \mathrm{~min}$ before measuring its absorbance at $540 \mathrm{~nm}$ [22]. ICP was used to determine total chromium in samples and standards using the method provided by the manufacturer.

\section{Results and Discussion}

\subsection{Effect of Contact Time}

Figure 1 shows the effect of contact time in the short term mode $(0-3 \mathrm{~h})$. The data reveal no dicsernible effect of particle size (original vs. powdered wool) on $\mathrm{Cr}(\mathrm{VI})$ removal efficiency. Furthermore, there is no apparent distinction between $\mathrm{Cr}(\mathrm{VI})$ and total chromium concentrations, indicating that $\mathrm{Cr}(\mathrm{VI})$ is virtually the only species present The maximum removal efficiency is $c a 88 \%$, in conformity with our previous findings [5] [6].

Figure 2 shows the effect of contact time on $\mathrm{Cr}(\mathrm{VI})$ removal in the long term mode $(0-165 \mathrm{~h})$. For both wool forms $\mathrm{Cr}(\mathrm{VI})$ was almost totally removed from solution after $100 \mathrm{~h}$. However, the total chromium concentration at $\mathrm{pH} 1.5$ decreased by $90 \%$ up to $120 \mathrm{~h}$ equilibration before rising at higher times. The increase in $\mathrm{Cr}(\mathrm{III})$ concentration with time is indicative of removal of $\mathrm{Cr}(\mathrm{VI})$ by wool, followed by reduction to $\mathrm{Cr}(\mathrm{III})$ and subsequent release of $\mathrm{Cr}(\mathrm{III})$ into solution. The sequence is further supported by FTIR data (see below). Control experiments in absence of wool indicate that $\mathrm{Cr}(\mathrm{VI})$ is relatively stable in both time modes.

\subsection{Effect of $\mathrm{pH}$}

The effect of $\mathrm{pH}$ on chromium removal efficiency is shown in Table 1 for the long term mode for the $\mathrm{pH}$ range $1.5-6.0$, from which it can be deduced that removal is favored by high acidity. This can be seen in Figure 2 which shows results at $\mathrm{pH} 1.5$ and $\mathrm{pH}$ 2.0.

On the other hand, short term mode studies (2-h contact time) showed no difference in removal at $\mathrm{pH} 1.5$ and 2.0. Table 1 also shows that the percent removal of $\mathrm{Cr}(\mathrm{VI})$ is much larger than that of total chromium, indicating speciation between $\mathrm{Cr}(\mathrm{VI})$ and $\mathrm{Cr}(\mathrm{III})$ [23] [24]. The acid catalyzed reduction of $\mathrm{Cr}(\mathrm{VI})$ to $\mathrm{Cr}(\mathrm{III})$ on wool may be represented by

$$
\mathrm{Cr}(\mathrm{VI})_{\mathrm{aq}}+\text { wool } \rightarrow \mathrm{Cr}(\mathrm{VI}) \text {-wool complex } \rightarrow \mathrm{Cr}(\mathrm{III}) \text {-wool complex } \rightarrow \mathrm{Cr}(\mathrm{III})_{\mathrm{aq}}+\text { wool }
$$

This mechanism is similar to that proposed in previous reports [20] [24] [25] for removal of Cr(VI) by other natural adsorbents. Table 1 shows the optimum $\mathrm{pH}$ for the removal of $\mathrm{Cr}(\mathrm{VI})$ by original wool is 1.5 .

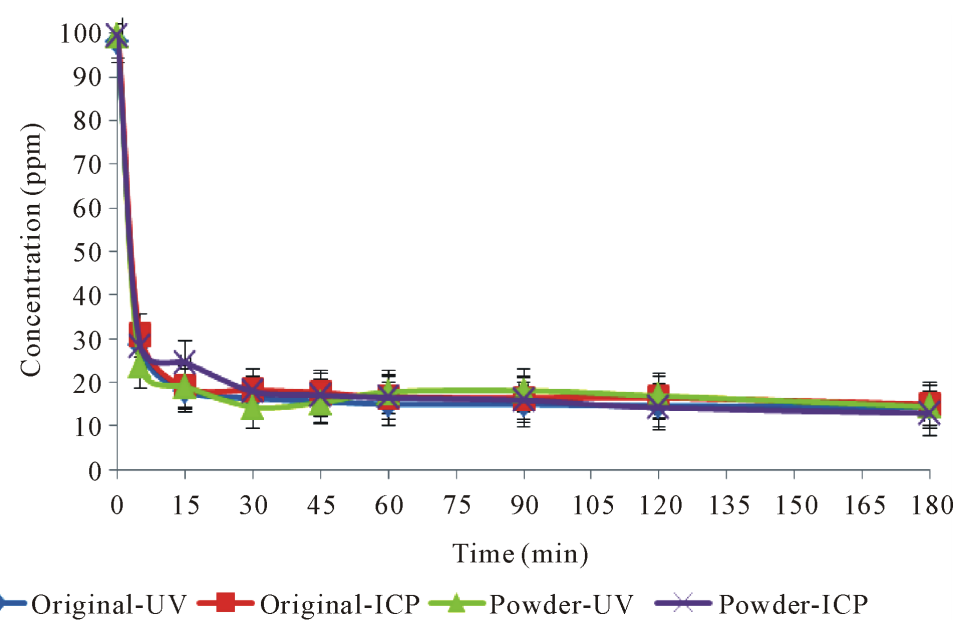

Figure 1. Variation of total $\mathrm{Cr}$ and $\mathrm{Cr}(\mathrm{VI})$ concentrations with time using original and powdered wool as adsorbents in the short term mode. Adsorbent dosage $=8.0 \mathrm{~g} / \mathrm{L}, \mathrm{pH}=2.0$ and $\mathrm{T}=25.0^{\circ} \mathrm{C}$, shaking speed $=150 \mathrm{rpm}$. 


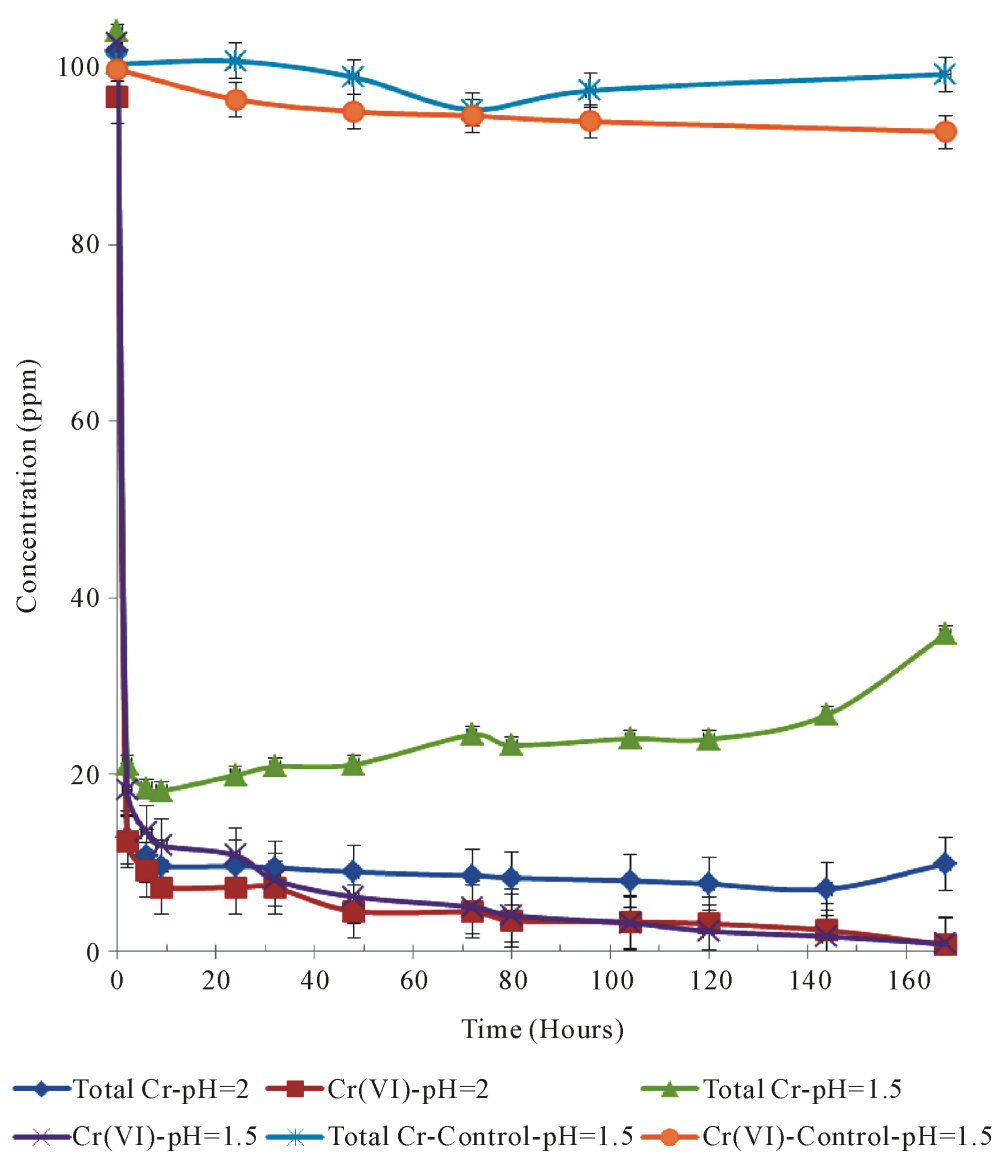

Figure 2. Changes in total chromium and $\mathrm{Cr}(\mathrm{VI})$ concentrations as a result of equilibration with wool in the long term mode. Adsorbent dosage $=8.0 \mathrm{~g} / \mathrm{L}$, $\mathrm{pH}=1.5$ and $2.0, \mathrm{~T}=25.0^{\circ} \mathrm{C}$, shaking speed $=150 \mathrm{rpm}$. Top two curves are control experiments in absence of wool.

Table 1. Percent removal of total chromium and $\mathrm{Cr}(\mathrm{VI})$ by original and powdered wools as a function of $\mathrm{pH}$ in the long term mode ( 5 days). Adsorbent dosage $=8.0 \mathrm{~g} / \mathrm{L}, \mathrm{T}=25.0^{\circ} \mathrm{C}$, shaking speed $=150 \mathrm{rpm}$. Concentrations are in ppm.

\begin{tabular}{|c|c|c|c|c|c|c|c|c|c|c|c|c|c|}
\hline & & \multicolumn{3}{|c|}{$\mathrm{pH}=1.5$} & \multicolumn{3}{|c|}{$\mathrm{pH}=2.0$} & \multicolumn{3}{|c|}{$\mathrm{pH}=4.0$} & \multicolumn{3}{|c|}{$\mathrm{pH}=6.0$} \\
\hline & & $\begin{array}{c}\text { Initial } \\
\text { Conc. } \\
\pm 0.7\end{array}$ & $\begin{array}{l}\text { Final } \\
\text { Conc. } \\
\pm 0.02\end{array}$ & $\begin{array}{c}\% \\
\text { Removal } \\
\pm 0.7\end{array}$ & $\begin{array}{l}\text { Initial } \\
\text { Conc. } \\
\pm 0.5\end{array}$ & $\begin{array}{l}\text { Final } \\
\text { Conc. } \\
\pm 0.03\end{array}$ & $\begin{array}{c}\% \\
\text { Removal } \\
\pm 1.0\end{array}$ & $\begin{array}{l}\text { Initial } \\
\text { Conc. } \\
\pm 1.5\end{array}$ & $\begin{array}{c}\text { Final } \\
\text { Conc. } \\
\pm 1.0\end{array}$ & $\begin{array}{c}\% \\
\text { Removal } \\
\pm 0.07\end{array}$ & $\begin{array}{c}\text { Initial } \\
\text { Conc. } \\
\pm 0.7\end{array}$ & $\begin{array}{l}\text { Final } \\
\text { Conc. } \\
\pm 0.6\end{array}$ & $\begin{array}{c}\% \\
\text { Removal } \\
\pm 0.05\end{array}$ \\
\hline \multirow{2}{*}{ Total Cr } & Original & 104.3 & 24.3 & 76.7 & 100 & 7.9 & 92.1 & 107.4 & 94.7 & 11.8 & 98.5 & 98.7 & 0 \\
\hline & Powdered & 104.3 & 25.9 & 75.2 & 100 & 4.2 & 95.8 & 107.4 & 87.3 & 18.7 & 98.5 & 95.5 & 3.0 \\
\hline \multirow{2}{*}{$\mathrm{Cr}(\mathrm{VI})$} & Original & 103.0 & 2.20 & 97.9 & 96.7 & 3.1 & 96.8 & 100 & 92.2 & 7.8 & 99.3 & 100.1 & 0 \\
\hline & Powdered & 103.0 & 5.50 & 94.7 & 96.7 & 9.7 & 90.0 & 100 & 88.3 & 11.7 & 99.3 & 100.7 & 0 \\
\hline
\end{tabular}

\subsection{Effect of Wool Dosage}

Figure 3 summarizes the effect of wool dosage on removal of $\mathrm{Cr}(\mathrm{VI})$ and total chromium at $\mathrm{pH}=2.0$, for a 5 -day contact time. The data show that the optimum dosage of wool is $8.0 \mathrm{~g} / \mathrm{L}$. Figure 3 also reveals that the extent of reduction of $\mathrm{Cr}(\mathrm{VI})$ in the long term mode is enhanced by higher dosages. Whereas $\mathrm{Cr}(\mathrm{VI})$ removal at dosages higher than $8.0 \mathrm{~g} / \mathrm{L}$ remains constant, total chromium removal is hindered by high dosages. This result may be explained by positing that high dosages serve to increase the rate of reduction of $\mathrm{Cr}(\mathrm{VI}) \mathrm{to} \mathrm{Cr}(\mathrm{III})$, followed by release of $\mathrm{Cr}(\mathrm{III})$ into solution. 


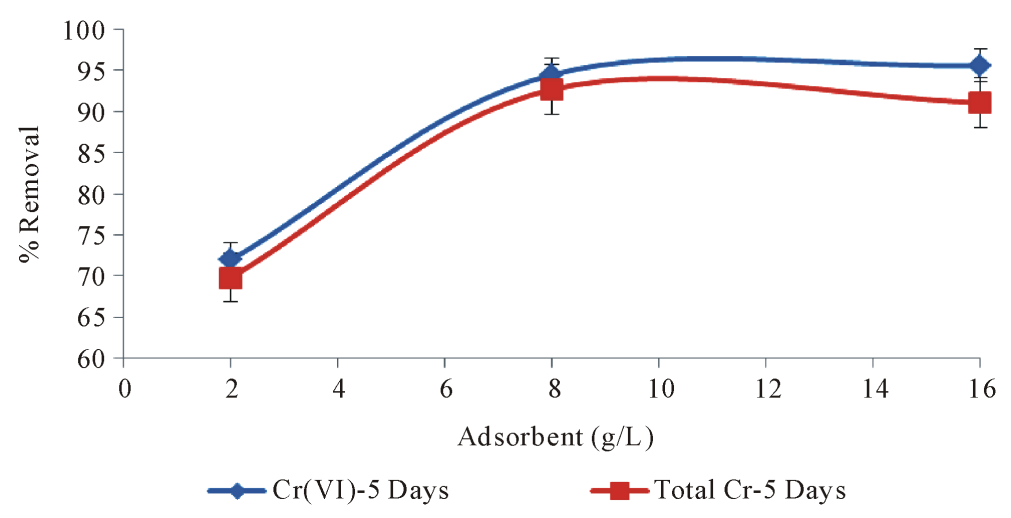

Figure 3. Variation of percent removal of total chromium and $\mathrm{Cr}(\mathrm{VI})$ with adsorbent dosage using original wool as adsorbent in long term contact time mode. Initial concentration of $\mathrm{Cr}(\mathrm{VI})=100 \mathrm{ppm}, \mathrm{pH}=2.0, \mathrm{~T}=25.0^{\circ} \mathrm{C}$, shaking speed $=150 \mathrm{rpm}$.

\subsection{Adsorption Isotherms}

Adsorption data were fitted to the Langmuir (Equation (2)) and Freundlich (Equation (3)) isotherms [3].

$$
\begin{gathered}
\mathrm{C}_{\mathrm{e}} / \mathrm{q}_{\mathrm{e}}=1 / \mathrm{Qb}+\mathrm{C}_{\mathrm{e}} / \mathrm{Q} \\
\mathrm{q}_{\mathrm{e}}=\mathrm{K}_{\mathrm{f}} \mathrm{C}_{\mathrm{e}}^{1 / \mathrm{n}}
\end{gathered}
$$

where $C_{e}$ is the equilibrium concentration of total chromium (mg/L), $q_{e}$ is the amount adsorbed at equilibrium, in $\mathrm{mg} / \mathrm{g}$ adsorbent. Q (mg/g) and b (L/mg) are the Langmuir constants, representing adsorption capacity and energy, respectively. $\mathrm{K}_{\mathrm{f}}$ and $\mathrm{n}$ are the Freundlich constants.

Figure 4 gives the variation of q with the equilibrium concentration of $\mathrm{Cr}(\mathrm{VI})$ in the long term contact time mode. The data reveal that $\mathrm{q}$ follows the same pattern at $\mathrm{pH} 1.5$ and 2.0, the asymptotic trend indicating a monolayer. The Langmuir isotherm gives a good fit for the data (Figure 5). However, the dependence of the term $\mathrm{C}_{\mathrm{e}} / \mathrm{q}_{\mathrm{e}}$ on equilibrium concentration in the long term mode does not obey this isotherm, indicating that calculations based on total chromium in solution cannot be attributed to $\mathrm{Cr}(\mathrm{VI})$ alone. Thus speciation of chromium takes place, with release of $\mathrm{Cr}(\mathrm{III})$ into solution following reduction of adsorbed $\mathrm{Cr}(\mathrm{VI})$. This finding demonstrates the efficacy of species resolved techniques in the study of adsorption isotherms for this type of complex system. By contrast, an earlier study using short term equilibration (2-h contact time) revealed that adsorption data for total chromium obeyed the Langmuir isotherm [3]. For this mode both $\mathrm{Cr}(\mathrm{VI})$ and total chromium fit this isotherm (Figure 6). These results may be explained by a two-step mechanism. The first is adsorption on wool accompanied by rapid equilibrium, and the second is a slow reduction of $\operatorname{Cr}(\mathrm{VI})$ to $\mathrm{Cr}(\mathrm{III})$, followed by release of $\mathrm{Cr}(\mathrm{III})$ into solution. Results for the short term mode reflected primarily the fast first step.

Figure 5 and Figure 6 yield the Langmuir parameters for short and long term modes. Table 2 summarizes the results for total chromium and $\mathrm{Cr}(\mathrm{VI})$ and shows that $\mathrm{Q}$ is larger for $\mathrm{Cr}(\mathrm{VI})$ in the long term mode and is also larger than that for total chromium in both modes. This indicates that in long term mode, more sites are available for $\mathrm{Cr}(\mathrm{VI})$ than in short term mode. This finding may be explained by postulating that some sites occupied by $\mathrm{Cr}(\mathrm{VI})$ undergo simultaneous reduction and release of $\mathrm{Cr}(\mathrm{III})$ to the solution.

Table 3 summarizes the fit of the data to the Freundlich isotherm Inspection of this table reveals that the correlation coefficient for both $\mathrm{Cr}(\mathrm{VI})$ and total chromium in the short term mode is smaller than that for Langmuir isotherm (Table 2). By contrast, for the long term mode, total chromium data obey the Freundlich, but not the Langmuir, isotherm. This indicates the non-ideality of total chromium adsorption which in turn may be attributed to the proposed mechanism above. Upon comparing the maximum adsorption capacity (Q) obtained under long term equilibration with values previously reported for low cost adsorbents [21] [22] [26]-[30], the value obtained in this work is among the highest $5 \%$.

Previously reported data on the elution profile of Cr(VI) from columns packed with wool [19] had been based solely on ICP, which measures total chromium. The authors had assumed that all $\mathrm{Cr}(\mathrm{VI})$ is retained after passing through the column, and had not considered the possibility of reduction to $\mathrm{Cr}(\mathrm{III})$. Reduction may indeed not 


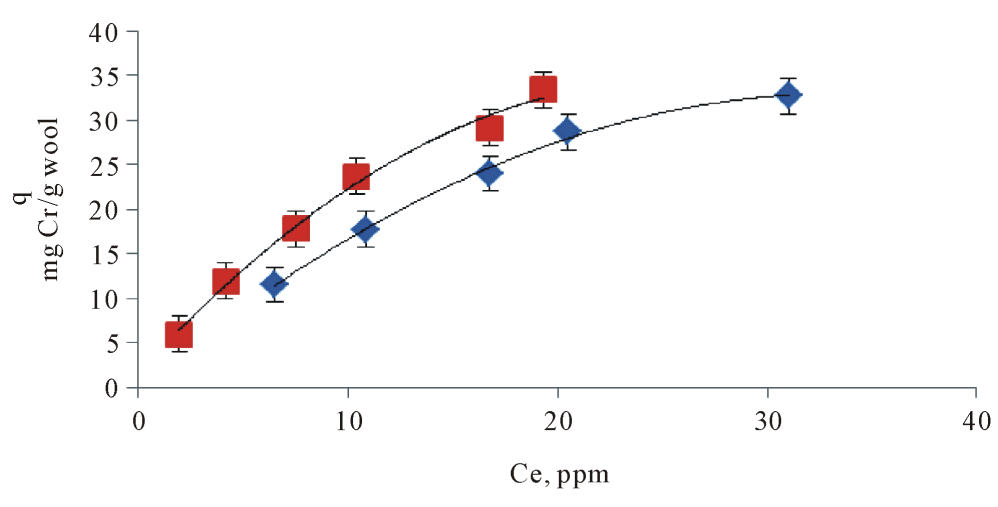

$\bullet \mathrm{pH}=1.5 \square \mathrm{pH}=2$

Figure 4. Amount of chromium removed in $\mathrm{mg} / \mathrm{g}$ (q) by trimmed original wool as function of $\mathrm{Ce}$, the equilibrium concentration of $\mathrm{Cr}(\mathrm{VI})$. Adsorbent dosage $=8.0 \mathrm{~g} / \mathrm{L}, \mathrm{T}=25.0^{\circ} \mathrm{C}$, shaking speed $=150 \mathrm{rpm}$.

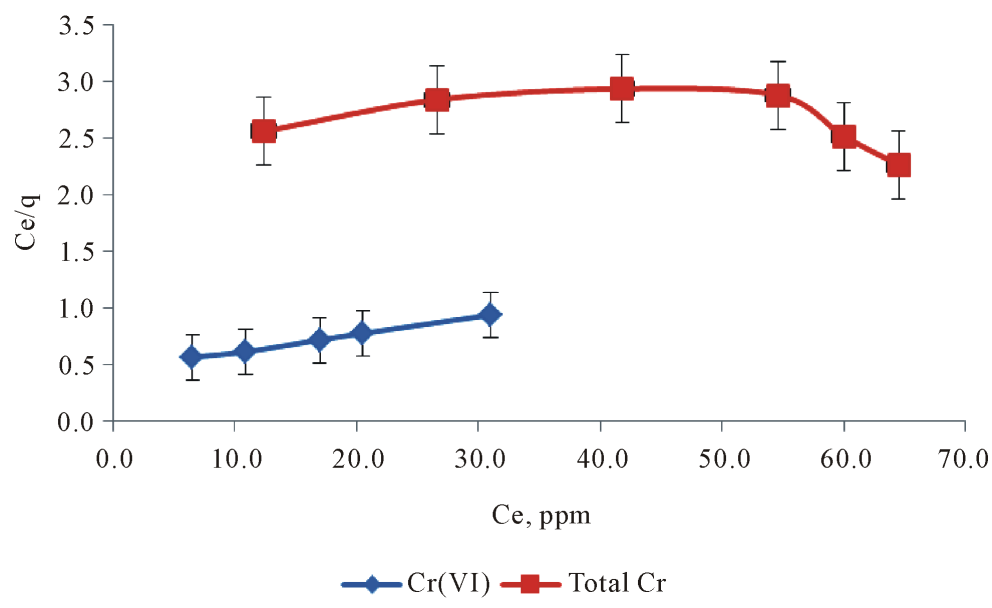

Figure 5. Langmuir isotherm for $\mathrm{Cr}(\mathrm{VI})$ and total chromium using original wool as adsorbent in long term mode ( 5 days). Adsorbent dosage $=8.0 \mathrm{~g} / \mathrm{L}$, $\mathrm{pH}=1.5, \mathrm{~T}=25.0^{\circ} \mathrm{C}$, shaking speed $=150 \mathrm{rpm}$.

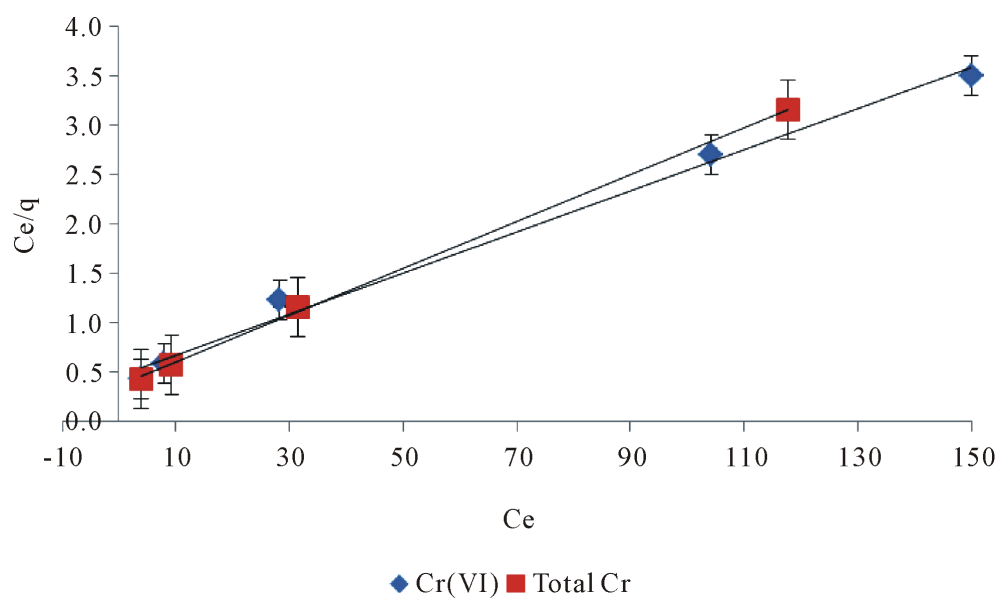

Figure 6. Langmuir isotherm for $\mathrm{Cr}(\mathrm{VI})$ and total chromium using original wool as adsorbent in short term mode (contact time $3 \mathrm{~h}$ ). Adsorbent dosage $=$ $8.0 \mathrm{~g} / \mathrm{L}, \mathrm{pH}=1.5, \mathrm{~T}=25.0^{\circ} \mathrm{C}$, shaking speed $=150 \mathrm{rpm}$. 
Table 2. Langmuir parameters (b, Q and $\mathrm{R}^{2}$ ) for total chromium and $\mathrm{Cr}(\mathrm{VI})$ for short term and long term equilibration periods, with original wool as adsorbent. Adsorbent dosage $=8.0 \mathrm{~g} / \mathrm{L}, \mathrm{T}=25.0^{\circ} \mathrm{C}$, shaking speed $=150 \mathrm{rpm}$.

\begin{tabular}{|c|c|c|c|}
\hline \multicolumn{4}{|c|}{ Short term mode (3-h contact time, $\mathrm{pH}=1.5$ ) } \\
\hline & $\begin{array}{c}\mathrm{b} \\
\pm 0.002\end{array}$ & $\begin{array}{c}\mathrm{Q} \\
\pm 0.2\end{array}$ & $\mathrm{R}^{2}$ \\
\hline Total Cr & 0.0061 & 48.5 & 0.999 \\
\hline $\operatorname{Cr}(\mathrm{VI})$ & 0.0095 & 38.0 & 0.997 \\
\hline \multicolumn{4}{|c|}{ Long term mode (5-day contact time, $\mathrm{pH}=1.5$ ) } \\
\hline & $\begin{array}{c}\mathrm{b} \\
\pm 0.002\end{array}$ & $\begin{array}{c}\mathrm{Q} \\
\pm 0.2\end{array}$ & $\mathrm{R}^{2}$ \\
\hline Total Cr & \multicolumn{3}{|c|}{ Nonlinear plot } \\
\hline $\mathrm{Cr}(\mathrm{VI})$ & 0.034 & 64.5 & 0.997 \\
\hline \multicolumn{4}{|c|}{ Short term mode (3-h contact time, $\mathrm{pH}=2.0$ ) } \\
\hline & $\begin{array}{c}\mathrm{b} \\
\pm 0.002\end{array}$ & $\begin{array}{c}\mathrm{Q} \\
\pm 0.2\end{array}$ & $\mathrm{R}^{2}$ \\
\hline Total Cr & 0.066 & 42.0 & 0.999 \\
\hline $\mathrm{Cr}(\mathrm{VI})$ & 0.047 & 48.5 & 0.994 \\
\hline \multicolumn{4}{|c|}{ Long term mode (5-day contact time, $\mathrm{pH}=2.0$ ) } \\
\hline & $\begin{array}{c}\mathrm{b} \\
\pm 0.001\end{array}$ & $\begin{array}{c}\mathrm{Q} \\
\pm 0.2\end{array}$ & $\mathrm{R}^{2}$ \\
\hline Total Cr & 0.0485 & 41.8 & 0.995 \\
\hline $\mathrm{Cr}(\mathrm{VI})$ & 0.0522 & 64.9 & 0.978 \\
\hline
\end{tabular}

Table 3. Freundlich isotherm parameters $\left(\mathrm{K}_{\mathrm{f}}, \mathrm{n}\right.$ and $\left.\mathrm{R}^{2}\right)$ for total chromium and $\mathrm{Cr}(\mathrm{VI})$ for short and long term modes using trimmed wool as adsorbent. Adsorbent dosage $=8.0 \mathrm{~g} / \mathrm{L}, \mathrm{T}=25.0^{\circ} \mathrm{C}$, shaking speed $=150 \mathrm{rpm}$.

\begin{tabular}{|c|c|c|c|}
\hline \multicolumn{4}{|c|}{ Short term mode (3-h contact time, $\mathrm{pH}=1.5$ ) } \\
\hline & $\begin{array}{c}\mathrm{K}_{\mathrm{f}} \\
\pm 0.02\end{array}$ & $\begin{array}{c}\mathrm{n} \\
\pm 0.02\end{array}$ & $\mathrm{R}^{2}$ \\
\hline Total Cr & 0.942 & 1.22 & 0.996 \\
\hline $\mathrm{Cr}(\mathrm{VI})$ & 0.631 & 1.34 & 0.992 \\
\hline \multicolumn{4}{|c|}{ Long term mode (5-day contact time, $\mathrm{pH}=1.5$ ) } \\
\hline & $\begin{array}{c}\mathrm{K}_{\mathrm{f}} \\
\pm 0.02\end{array}$ & $\begin{array}{c}\mathrm{n} \\
\pm 0.02\end{array}$ & $\mathrm{R}^{2}$ \\
\hline Total Cr & 0.307 & 0.940 & 0.981 \\
\hline $\mathrm{Cr}(\mathrm{VI})$ & 2.988 & 1.360 & 1.000 \\
\hline \multicolumn{4}{|c|}{ Short term mode $(3-\mathrm{h}$ contact time, $\mathrm{pH}=2.0$ ) } \\
\hline & $\begin{array}{c}\mathrm{K}_{\mathrm{f}} \\
\pm 0.02\end{array}$ & $\begin{array}{c}\mathrm{n} \\
\pm 0.02\end{array}$ & $\mathrm{R}^{2}$ \\
\hline Total Cr & 5.999 & 2.478 & 0.969 \\
\hline $\mathrm{Cr}(\mathrm{VI})$ & 4.997 & 2.191 & 0.992 \\
\hline \multicolumn{4}{|c|}{ Long term mode (5-day contact time, $\mathrm{pH}=2.0$ ) } \\
\hline & $\begin{array}{c}\mathrm{K}_{\mathrm{f}} \\
\pm 0.02\end{array}$ & $\begin{array}{c}\mathrm{n} \\
\pm 0.02\end{array}$ & $\mathrm{R}^{2}$ \\
\hline Total Cr & 0.178 & 0.609 & 0.985 \\
\hline Cr(VI) & 0.172 & 0.755 & 0.985 \\
\hline
\end{tabular}


occur when the contact time between wool and the eluent is very short. Under such conditions, all forms of chromium are essentially removed. However, when solutions containing $\mathrm{Cr}(\mathrm{VI})$ were left in contact with wool in the column for longer periods, the first fraction contained higher concentrations of total chromium, and this can now be attributed to the presence of $\mathrm{Cr}(\mathrm{III})$. To verify this conclusion, $100 \mathrm{ppm} \mathrm{Cr}(\mathrm{VI})$ solution was applied to a column packed with original wool and eluted at a constant rate of $2.0 \mathrm{ml} / \mathrm{min}$. $100 \mathrm{ml}$ fractions of eluents, representing short term equilibration were collected for four successive overnight periods, with the elution stopped at the end of each day, thereby allowing long term equilibration of $\operatorname{Cr}(\mathrm{VI})$ on wool. The data for total chromium and $\mathrm{Cr}(\mathrm{VI})$ are presented in Figure 7. Virtually, the only form of chromium eluted overnight is $\mathrm{Cr}(\mathrm{III})$. This corroborates the finding that upon prolonged exposure on wool, $\mathrm{Cr}(\mathrm{VI})$ undergoes reduction to Cr(III).

\subsection{FTIR Spectroscopy}

Figure 8 displays FTIR spectra of wool before and after adsorption of $\mathrm{Cr}(\mathrm{VI})$. The very weak peak at $939 \mathrm{~cm}^{-1}$ in free wool becomes much more pronounced in wool loaded with chromium for long term contact, due to the oxidation of wool by $\mathrm{Cr}(\mathrm{VI})$. This peak can be attributed to $\mathrm{S}=\mathrm{O}$ bonds that form when cystine in wool is oxidized. A similar assignment has been reported for wool oxidized by UV irradiation [31]. This finding supports the proposed mechanism for removal of $\mathrm{Cr}(\mathrm{VI})$ by wool from aqueous solution (Equation (1)).

\subsection{Electron Dispersive X-Ray Spectroscopy (EDS)}

Scanning electron microscopy (SEM) was employed to study the surface of wool before and after loading with chromium. In order to obtain the elemental analysis of the surface, EDS spectra were recorded for both samples (Figure 9). Inspection of this figure reveals that chromium is retained on wool at the end of the long term contact time, with the appearance of a chloride peak from $\mathrm{HCl}$.

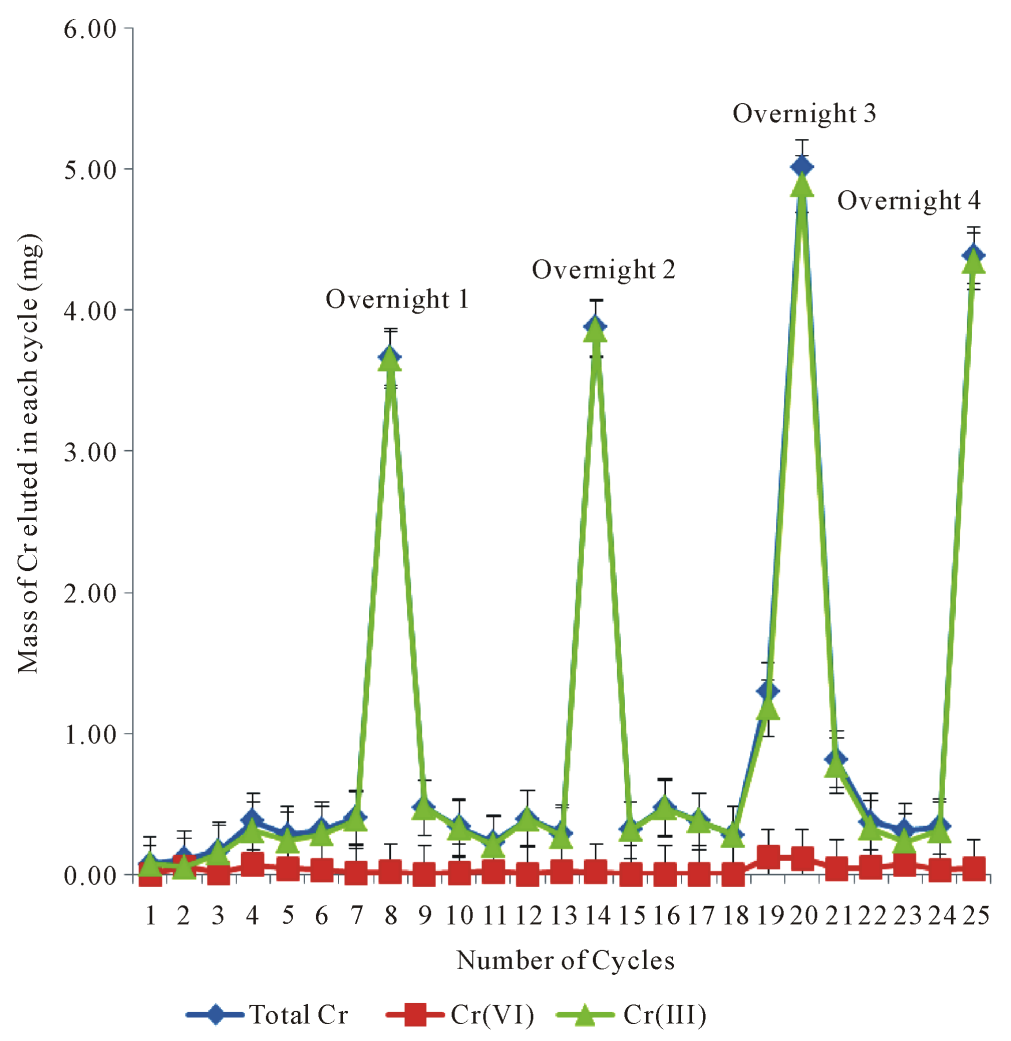

Figure 7. Mass of chromium species in eluted fractions. Fraction volume = $100 \mathrm{ml}$, total applied volume $=2.5 \mathrm{~L}, \mathrm{pH}$ of applied solution $=1.5$, wool mass $26.0 \mathrm{~g}$, wool depth $=29.0 \mathrm{~cm}$. T $=25.0^{\circ} \mathrm{C}$. 


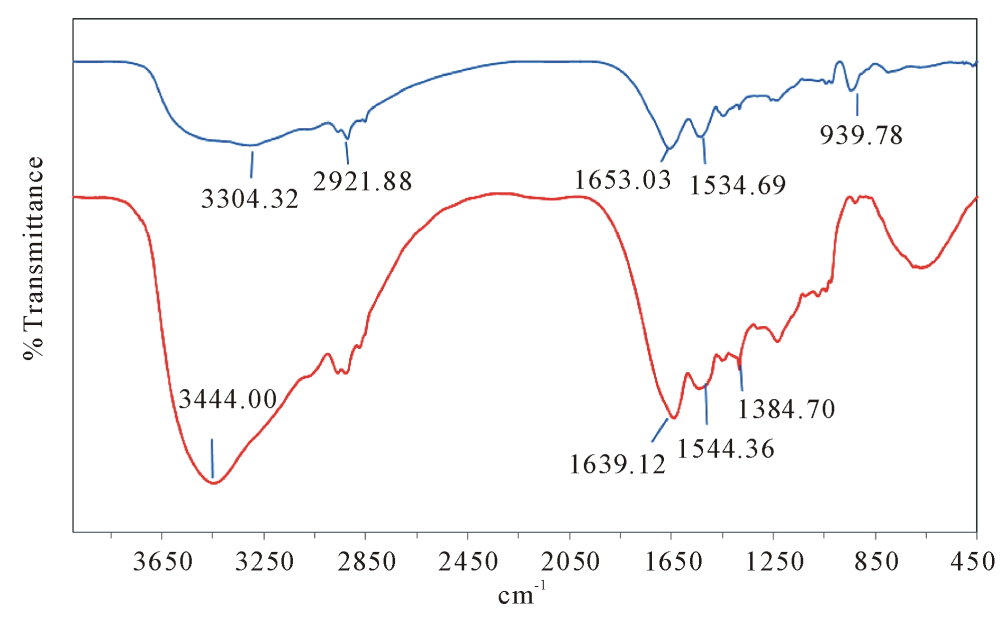

Figure 8. FTIR spectra of free wool (bottom) and wool loaded with ionic chromium species (top).

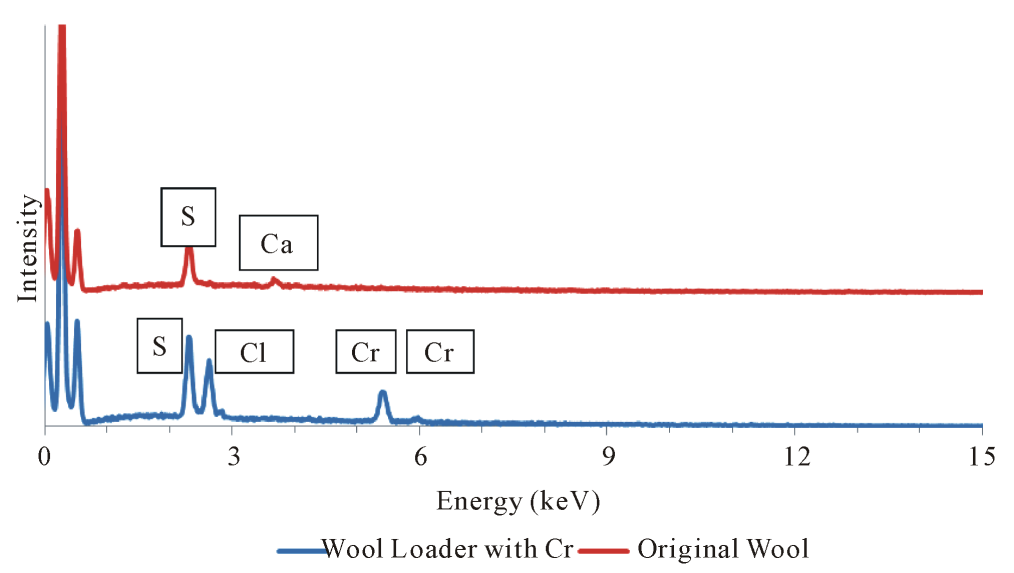

Figure 9. EDS results for original free wool (top) and wool loaded with ionic chromium species (bottom).

\section{Conclusion}

The affinity of wool for $\mathrm{Cr}(\mathrm{VI})$ varies with contact time and $\mathrm{pH}$. For short contact times, the Langmuir adsorption isotherm was obeyed with no detectable change in the oxidation state. However, removal percentages did not exceed 90\%. Long contact times resulted in more than 99\% removal of $\operatorname{Cr}(\mathrm{VI})$. A 2-step mechanism for this removal is proposed. The first involves fast adsorption of $\mathrm{Cr}(\mathrm{VI})$ on wool and the second a slow catalytic reduction of $\mathrm{Cr}(\mathrm{VI})$ to $\mathrm{Cr}(\mathrm{III})$, followed by desorption of $\mathrm{Cr}(\mathrm{III})$ into solution. The surface of wool before and after adsorption was characterized by FTIR and EDS and the results with the suggested mechanism. The optimum parameters for this significant improvement in $\mathrm{Cr}(\mathrm{VI})$ removal and hence its environmental remediation can now be identified as $\mathrm{pH} 1.5$, contact time of at least 5 days, and a minimum adsorbent dosage of $8.0 \mathrm{~g} / \mathrm{L}$. For the short term study, $\mathrm{pH} 2.0$ was selected so as to provide comparison with previous results. $\mathrm{Cr}(\mathrm{VI})$ adsorption follows the Langmuir adsorption isotherm with $\mathrm{Q}=64.5$. This high capacity of wool for $\mathrm{Cr}(\mathrm{VI})$ provides a practical solution for the removal of $\mathrm{Cr}(\mathrm{VI})$ from industrial wastewater. A plant can be constructed consisting of a batch adsorption reactor with a 5-day retention time in which $\mathrm{Cr}(\mathrm{VI})$ is mostly removed. The effluent could then subjected to $\mathrm{pH} 10.0$ at which $\mathrm{Cr}(\mathrm{III})$ precipitates as hydroxide which can be recovered by sand filtration for further reuse.

\section{Acknowledgements}

This research was supported by the American University of Sharjah, Grant FRG12-2-10. 


\section{References}

[1] Parikh, N. and Mashru, R. (2010) Estimation of Trace Amounts of Chromium(III) in Various Multivitamin Pharmaceutical Formulations. International Journal of Pharmacy and Biological Sciences, 1, 388-394.

[2] Kotas, J. and Stasicka, Z. (2000) Chromium Occurrence in the Environment and Methods of Its Speciation. Environmental Pollution, 107, 263-283. http://dx.doi.org/10.1016/S0269-7491(99)00168-2

[3] Dakiky, M., Khamis, M., Manassra, A. and Mer'eb, M. (2002) Selective Adsorption of Cr(VI) in Industrial Wastewater Using Low-Cost Abundantly Available Adsorbents. Advances in Environmental Research, 6, 533-540. http://dx.doi.org/10.1016/S1093-0191(01)00079-X

[4] Ezebuirol, P., Gandhi, J., Zhang, C., Mathew, J., Ritter, M. and Humphrey, M. (2012) Optimal Sample Preservation and Analysis of $\mathrm{Cr}(\mathrm{VI})$ in Drinking Water Samples by High Resolution Ion Chromatography Followed by Post Column Reaction and UV/Vis Detection. Journal of Analytical Sciences, Methods and Instrumentation, 2, 74-80. http://dx.doi.org/10.4236/jasmi.2012.22014

[5] Udy, M.J. (1956) History of Chromium. In: Udy, M.J., Ed., Chromium. Vol. I. Chemistry of Chromium and Its Compounds, Reinhold, New York, 1-13.

[6] Zhou, X., Korenaga, T., Takahashi, T., Moriwake, T. and Shinoda, S. (1993) A Process Monitoring Controlling System for the Treatment of Wastewater Containing Chromium(VI). Water Research, 27, 1049-1054. http://dx.doi.org/10.1016/0043-1354(93)90069-T

[7] Tiravanti, G., Petruzzelli, D. and Passino, R. (1997) Pretreatment of Tannery Wastewaters by an Ion Exchange Process for Cr(III) Removal and Recovery. Water Science and Technology, 36, 197-207. http://dx.doi.org/10.1016/S0273-1223(97)00388-0

[8] Seaman, J.C., Bertsch, P.M. and Schwallie, L. (1999) In Situ Cr(VI) Reduction within Coarse-Textured, Oxide-Coated Soil and Aquifer Systems Using Fe(II) Solutions. Environmental Science \& Technology, 33, 938-944. http://dx.doi.org/10.1021/es980546+

[9] Khamis, M., Jumean, F. and Abdo, N. (2009) Speciation and Removal of Chromium from Aqueous Solution by White, Yellow and Red UAE Sand. Journal of Hazardous Materials, 169, 948-952. http://dx.doi.org/10.1016/j.jhazmat.2009.04.053

[10] Dahbi, S., Azzi, M. and de la Guardia, M. (1999) Removal of Hexavalent Chromium from Wastewaters by Bone Charcoal. Fresenius' Journal of Analytical Chemistry, 363, 404-407. http://dx.doi.org/10.1007/s002160051210

[11] Kongsricharoern, N. and Polprasert, C. (1996) Chromium Removal by a Bipolar Electrochemical Precipitation Process. Water Science and Technology, 34, 109-116. http://dx.doi.org/10.1016/S0273-1223(96)00793-7

[12] Pagilla, K. and Canter, L.W. (1999) Laboratory Studies on Remediation of Chromium-Contaminated Soils. Journal of Environmental Engineering, 125, 243-248. http://dx.doi.org/10.1061/(ASCE)0733-9372(1999)125:3(243)

[13] Chakravarti, A.K., Chowdhury, S.B., Chakrabarty, S., Chakrabarty, T. and Mukherjee, D.C. (1995) Liquid Membrane Multiple Emulsion Process of Chromium (VI) Separation from Wastewaters. Colloids and Surfaces A: Physicochemical and Engineering Aspects, 103, 59-71. http://dx.doi.org/10.1016/0927-7757(95)03201-N

[14] Lin, C.F., Rou, W. and Lo, K.S. (1992) Treatment Strategy for Cr(VI)-Bearing Wastes. Water Science and Technology, 26, 2301-2304.

[15] Aksu, Z. and Kutsal, T. (1990) A Comparative Study for Biosorption Characteristics of Heavy Metal Ions with C. vulgaris. Environmental Technology, 11, 979-987. http://dx.doi.org/10.1080/09593339009384950

[16] Leyva-Ramos, R., Fuentes-Rubio, L., Guerrero-Coronado, R. and Mendoza-Barron, J. (1995) Adsorption of Trivalent Chromium from Aqueous Solutions onto Activated Carbon. Journal of Chemical Technology and Biotechnology, 62, 64-67. http://dx.doi.org/10.1002/jctb.280620110

[17] Samantaroy, S., Mohanty, A.K. and Misra, M. (1997) Removal of Hexavalent Chromium by Kendu Fruit Gum Dust. Journal of Applied Polymer Science, 66, 1485-1494. http://dx.doi.org/10.1002/(SICI)1097-4628(19971121)66:8<1485::AID-APP9>3.0.CO;2-A

[18] Namasivayam, C. and Yamuna, R.T. (1995) Adsorption of Chromium (VI) by a Low-Cost Adsorbent: Biogas Residual Slurry. Chemosphere, 30, 561-578. http://dx.doi.org/10.1016/0045-6535(94)00418-T

[19] Singh, D.B., Rupainwar, D.C. and Prasad, G. (1992) Studies on the Removal of Cr(VI) from Wastewater by Feldspar. Journal of Chemical Technology and Biotechnology, 53, 127-131. http://dx.doi.org/10.1002/jctb.280530204

[20] Manassra, A., Khamis, M., Ihmied, T. and Eldakiky, M. (2010) Removal of Chromium by Continuous Flow Using Wool Packed Columns. Electronic Journal of Environmental, Agricultural and Food Chemistry, 9, 651-663.

[21] Vinodhini, V. and Nilanjana, D. (2009) Mechanism of Cr(VI) Biosorption by Neem Sawdust. Journal of Scientific Research, 4, 324-329. 
[22] Qurie, M., Khamis, M., Manassra, A., Ayyad, I., Nir, S., Scrano, L., Bufo, S. and Karamam, R. (2013) Removal of Cr(VI) from Aqueous Environments Using Micelle-Clay Adsorption. Scientific World Journal, 2013, Article ID: 942703. http://dx.doi.org/10.1155/2013/942703

[23] Zghida, H., Baouab, M. and Gauthier, R. (2003) Sorption of Chromium Oxy-Anions onto Cationized Ligno-Cellulosic Materials. Journal of Applied Polymer Science, 87, 1660-1665. http://dx.doi.org/10.1002/app.11596

[24] EPAA (1992) Chromium Hexavalent (Colorimetric), EPA Method 7196A1992. http://www.epa.gov/osw/hazard/testmethods/sw846/pdfs/7196a.pdf

[25] Fiol, N., Escudero, C. and Villaescusa, I. (2008) Chromium Sorption and Cr(VI) Reduction to Cr(III) by Grape Stalks and Yohimbe Bark. Bioresource Technology, 99, 5030-5036. http://dx.doi.org/10.1016/j.biortech.2007.09.007

[26] Daneshvar, N., Salari, D. and Aber, S. (2002) Chromium Adsorption and Cr(VI) Reduction to Trivalent Chromium in Aqueous Solutions by Soya Cake. Journal of Hazardous Materials, 94, 49-61. http://dx.doi.org/10.1016/S0304-3894(02)00054-7

[27] Nakano, Y., Takeshita, K. and Tsutsumi, T. (2001) Adsorption Mechanism of Hexavalent Chromium by Redox within Condensed-Tannin Gel. Water Research, 35, 496-500. http://dx.doi.org/10.1016/S0043-1354(00)00279-7

[28] Tan, W.T., Ooi, S.T. and Lee, C.K. (1993) Removal of Chromium(VI) from Solution by Coconut Husk and Palm Pressed Fibers. Environmental Technology, 14, 277-282. http://dx.doi.org/10.1080/09593339309385290

[29] Singh, D.K., Saksena, D.N. and Tiwari, D.P. (1994) Removal of Chromium(VI) from Aqueous Solutions. Indian Journal of Environmental Health, 36, 272-277.

[30] Cho, N.S., Aoyama, M., Seki, K., Hayashi, N. and Doi, S. (1999) Adsorption by Coniferous Leaves of Chromium Ions from Effluent. Journal of Wood Science, 45, 266-270. http://dx.doi.org/10.1007/BF01177738

[31] Millington, K. and Church, J. (1997) The Photodegradation of Wool Keratin II. Proposed Mechanisms Involving Cysteine. Journal of Photochemistry and Photobiology B: Biology, 39, 204-212. http://dx.doi.org/10.1016/S1011-1344(96)00020-6 
Scientific Research Publishing (SCIRP) is one of the largest Open Access journal publishers. It is currently publishing more than 200 open access, online, peer-reviewed journals covering a wide range of academic disciplines. SCIRP serves the worldwide academic communities and contributes to the progress and application of science with its publication.

Other selected journals from SCIRP are listed as below. Submit your manuscript to us via either submit@scirp.org or Online Submission Portal.
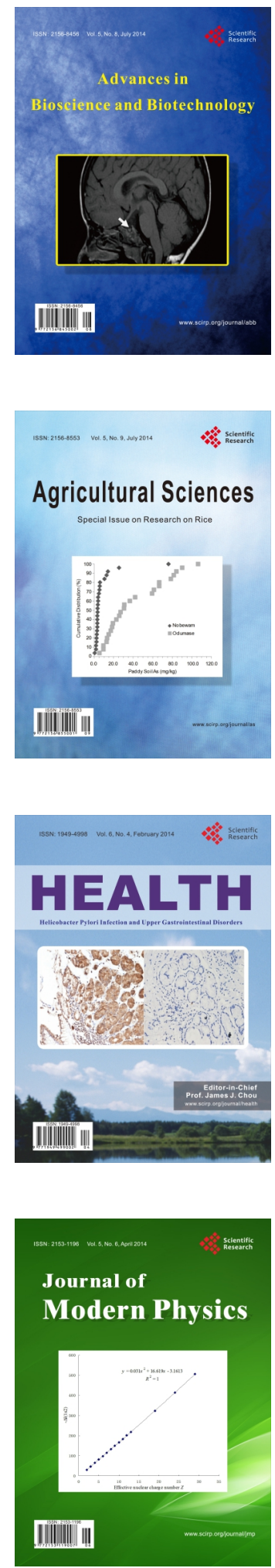
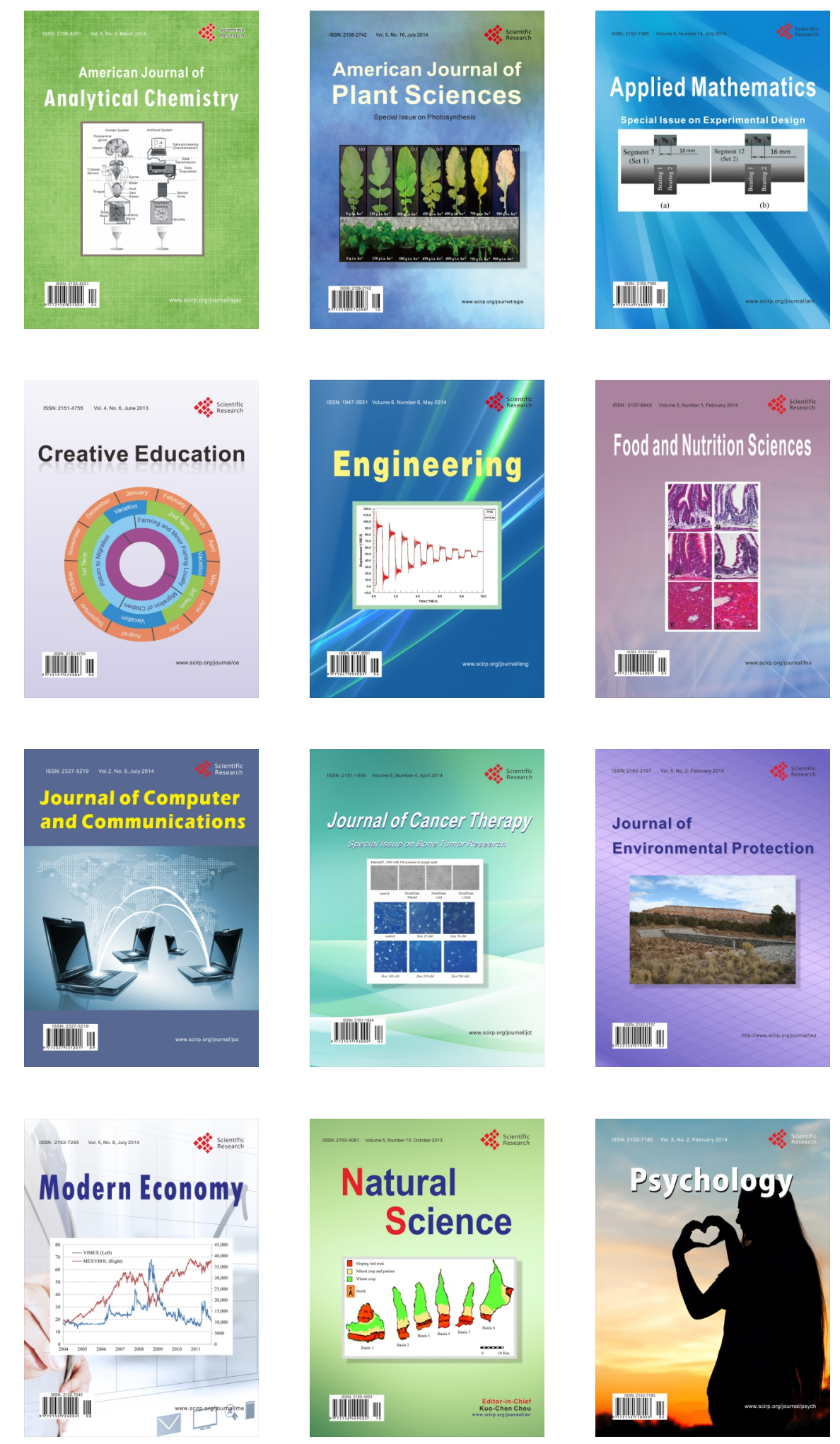